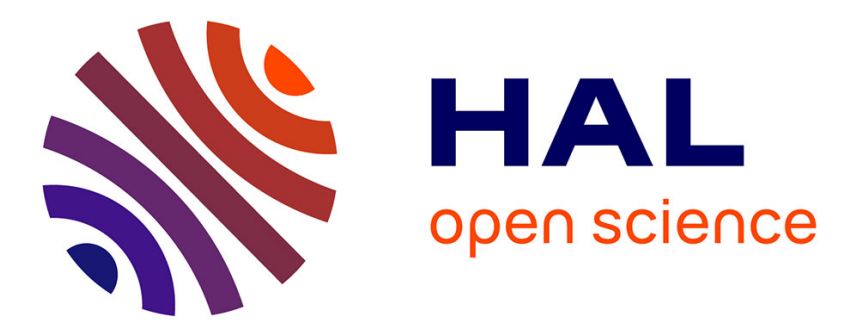

\title{
Comparative study of two atomic layer etching processes for $\mathrm{GaN}$
}

\author{
Cédric Mannequin, Christophe Vallée, Katsuhiro Akimoto, Thierry \\ Chevolleau, Christophe Durand, Christian Dussarrat, Takashi Teramoto, \\ Etienne Gheeraert, Henri Mariette
}

\section{To cite this version:}

Cédric Mannequin, Christophe Vallée, Katsuhiro Akimoto, Thierry Chevolleau, Christophe Durand, et al.. Comparative study of two atomic layer etching processes for GaN. Journal of Vacuum Science \& Technology A, 2020, 38 (3), pp.032602. 10.1116/1.5134130 . hal-02917577

\section{HAL Id: hal-02917577 \\ https: / hal.univ-grenoble-alpes.fr/hal-02917577}

Submitted on 22 Sep 2021

HAL is a multi-disciplinary open access archive for the deposit and dissemination of scientific research documents, whether they are published or not. The documents may come from teaching and research institutions in France or abroad, or from public or private research centers.
L'archive ouverte pluridisciplinaire HAL, est destinée au dépôt et à la diffusion de documents scientifiques de niveau recherche, publiés ou non, émanant des établissements d'enseignement et de recherche français ou étrangers, des laboratoires publics ou privés. 


\section{Comparative study of two atomic layer etching processes for GaN $\odot$}

Cite as: J. Vac. Sci. Technol. A 38, 032602 (2020); https://doi.org/10.1116/1.5134130

Submitted: 30 October 2019 . Accepted: 03 March 2020 . Published Online: 26 March 2020

Cédric Mannequin, Christophe Vallée, Katsuhiro Akimoto, Thierry Chevolleau, Christophe Durand, Christian Dussarrat, Takashi Teramoto, (i) Etienne Gheeraert, Henri Mariette, et al.

\section{COLLECTIONS}

Paper published as part of the special topic on Special Topic Collection on Atomic Layer Etching (ALE)

F This paper was selected as Featured
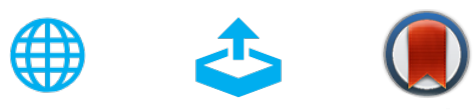

\section{ARTICLES YOU MAY BE INTERESTED IN}

\section{Overview of atomic layer etching in the semiconductor industry}

Journal of Vacuum Science \&amp; Technology A 33, 020802 (2015); https://

doi.org/10.1116/1.4913379

Selective atomic layer etching of $\mathrm{HfO}_{2}$ over silicon by precursor and substrate-dependent selective deposition

Journal of Vacuum Science \&amp; Technology A 38, 032601 (2020); https:// doi.org/10.1116/1.5143247

Inside the mysterious world of plasma: A process engineer's perspective Journal of Vacuum Science \&amp; Technology A 38, 031004 (2020); https:// doi.org/10.1116/1.5141863

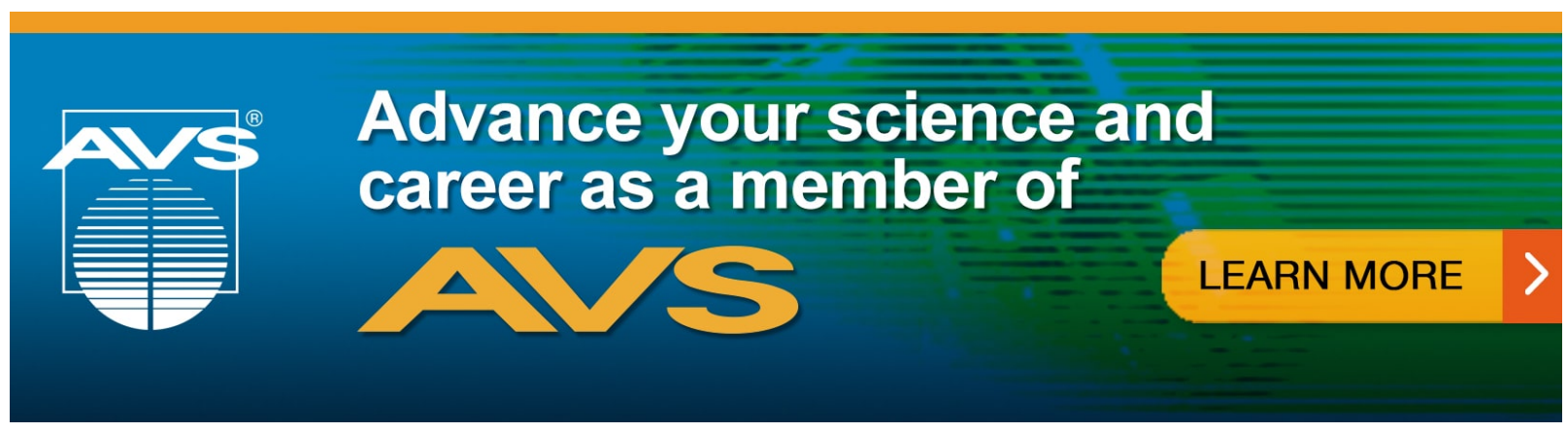




\title{
Comparative study of two atomic layer etching processes for GaN
}

\author{
Cite as: J. Vac. Sci. Technol. A 38, 032602 (2020); doi: $10.1116 / 1.5134130$ \\ Submitted: 30 October 2019 . Accepted: 3 March 2020 . \\ Published Online: 26 March 2020
}

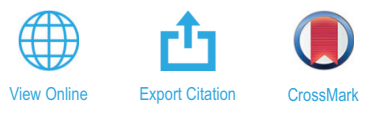

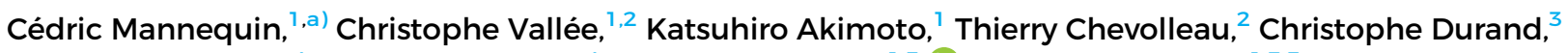
Christian Dussarrat, ${ }^{4}$ Takashi Teramoto, ${ }^{4}$ Etienne Gheeraert, ${ }^{1,5}$ (DD and Henri Mariette ${ }^{1,3,5}$

\author{
AFFILIATIONS \\ ${ }^{1}$ Institute of Applied Physics, Faculty of Pure and Applied Sciences, University of Tsukuba, Tsukuba 305-8573, Japan \\ ${ }^{2}$ CNRS/LTM, University of Grenoble-Alpes, Grenoble 38000, France \\ ${ }^{3}$ CEA/IRIG/PHELIQS, University of Grenoble-Alpes, Grenoble 38054, France \\ ${ }^{4}$ Air Liquide Laboratories, Yokosuka 239-0847, Japan \\ ${ }^{5} \mathrm{CNRS} /$ Institut Néel, University of Grenoble-Alpes, Grenoble 38042, France
}

Note: This paper is part of the 2020 Special Topic Collection on Atomic Layer Etching (ALE).

a)Electronic mail: mannequin.cedric.ga@u.tsukuba.ac.jp

\begin{abstract}
Atomic layer etching (ALE) of Ga-polar GaN (0001) using a standard inductively coupled plasma-reactive ion etching system is achieved in this work. The sequential process is using $\mathrm{Cl}_{2}$ to modify the surface in the adsorption step. For the activation step, the authors compare two rare gas plasmas, namely, Ar and $\mathrm{Kr}$, and show a much larger and well-defined ALE window for the latter. The ALE of GaN is demonstrated by etching mesa structures masked with a photoresist. A constant etching rate per cycle of two monolayers is obtained. The experimental conditions of this self-limited process are found by changing both the adsorption and activation times, together with the source power. This provides an atomic-scale process for nanofabrication, with significant improvements to the GaN surface.
\end{abstract}

Published under license by AVS. https://doi.org/10.1116/1.5134130

\section{INTRODUCTION}

One of the greatest characteristics of gallium nitride $(\mathrm{GaN})$ and its related alloys with In and/or Al for applications in highpower microelectronic devices, such as power light emitting diode and high electron mobility transistors, is their strong bonding energies $^{1,2}$ of $11.5,8.9$, and $7.7 \mathrm{eV} /$ bond for $\mathrm{AlN}, \mathrm{GaN}$, and $\mathrm{InN}$, respectively. However, this chemical stability is a critical issue when dealing with the dry etching process of these nitride devices because it requires high ionic flux at high energies. Such plasma etching induces a lot of surface damage that is detrimental to the device performances; see the progress review by Eriguchi. ${ }^{3}$ For example, the damage induced during the fabrication process of a recessed gate for an $\mathrm{AlGaN} / \mathrm{GaN}$ field effect transistor could drastically reduce the gate breakdown voltage. ${ }^{4}$ Similarly, when dealing with optoelectronic devices, point defects induced by the etching can act as Shockley-Read-Hall nonradiative centers for the carriers $^{5}$ and/or as surface charged traps, which leads to Fermi-level pinning. ${ }^{6}$ Moreover, by using a (0001) surface, the formation of a nonstoichiometric surface appears due to preferential etching loss of one of the elements $\mathrm{Ga}$ or $\mathrm{N}$.'

To overcome all these problems, atomic layer etching (ALE) processes are developed nowadays. ALE is a sequential and cyclic process, allowing, in principle, an atomically controlled layer-bylayer and selective etching of a targeted material. The ALE basic concept is to split the etch process into at least two separate steps: first modifying the surface and second removing the thin modified layer; ${ }^{8}$ see Fig. 1(a). Moreover, ALE relies on the fact that both these steps, named hereafter adsorption and activation, respectively, are self-limited. The adsorption step amounts to controlled surface modification ideally to one monolayer (ML), ${ }^{9}$ while the activation step relies on a controlled reaction to remove the upmost modified layer by thermal reaction, ionic bombardment, or photon irradiation. Then, the ALE process offers a more precise control by isolating steps in time and switching between the steps in a repeatable cycle, together with a less ion-induced damage. ALE is under development nowadays to achieve atomic-scale control for nanoscale 
(a)
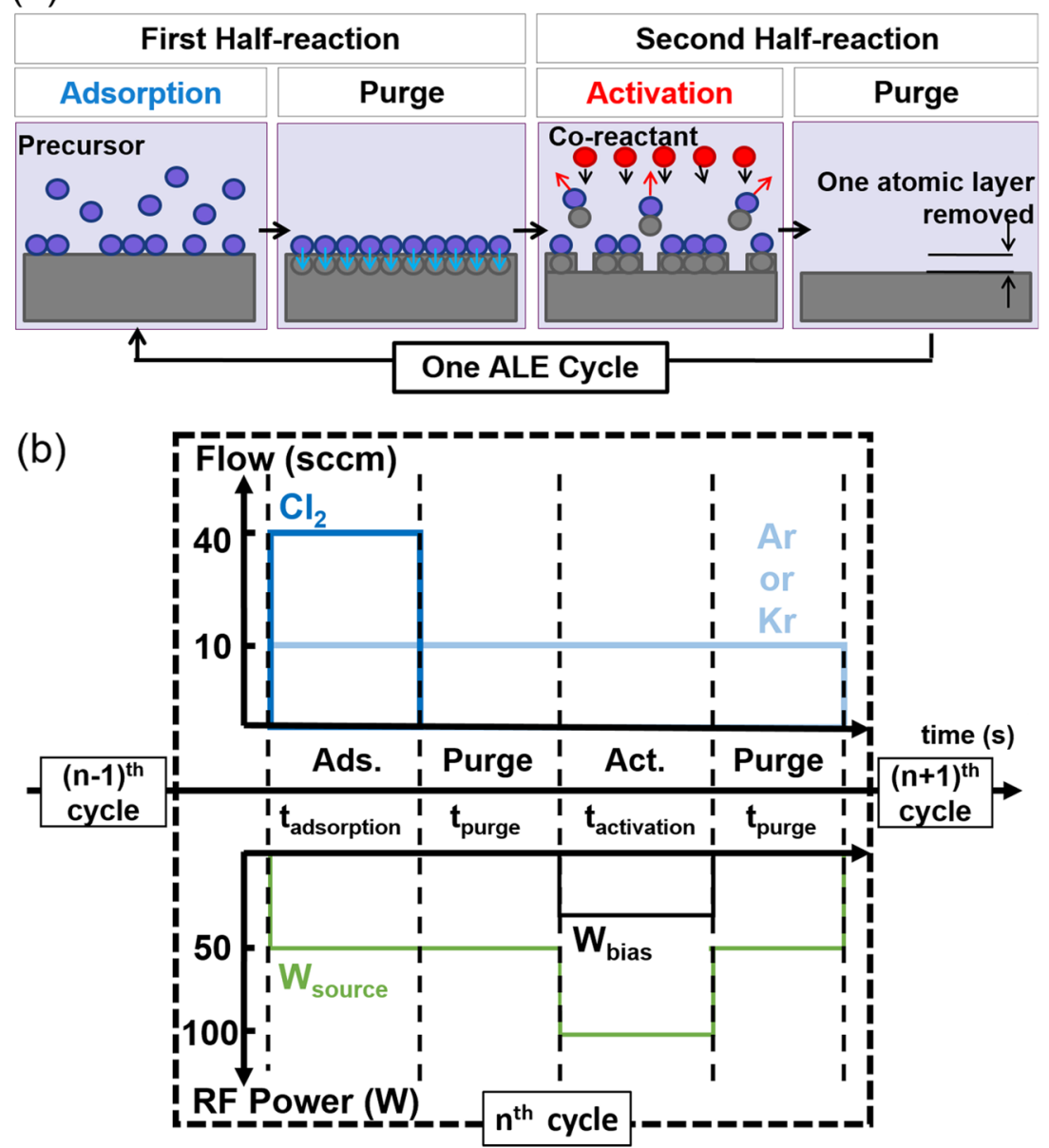

FIG. 1. Schematic representation of the two ALE half reactions: adsorption and activation (a). Schematic representation of one ALE cycle used in this study (b): a gas mixture consisting of $\mathrm{Cl}_{2}$ and $\mathrm{Ar}$ or $\mathrm{Kr}$ at 40 and 10 SCCM, respectively, is used for the adsorption step. A constant flow of rare gas at 10 SCCM ( $\mathrm{Ar}$ or $\mathrm{Kr}$ ) is permanently maintained for the purge and activation step. $\mathrm{RF}_{\text {source }}$ is maintained at $50 \mathrm{~W}$ for the adsorption step and the purge step and is increased to 100 or $120 \mathrm{~W}$ during the activation step. $\mathrm{RF}_{\text {bias }}$ is only applied during the activation step in the $15-50 \mathrm{~W}$ range. device fabrication for various materials including semiconductors, metals, and dielectrics; see the paper by Kanarik et al. ${ }^{10}$

For GaN, the reported plasma assisted ALE relies-regarding the adsorption step-either on oxidation, using $\mathrm{O}_{2}$ plasma ${ }^{11,12}$ or $\mathrm{H}_{2} \mathrm{O}_{2}$ solution, ${ }^{13}$ or on chlorination of $\mathrm{GaN}$ surfaces to form $\mathrm{GaCl}_{\mathrm{x}}$ by-products. ${ }^{14,15}$ For the activation step, the use of Ar ion bombardment enables a unidirectional reaction, which is required for patterned features. $^{14,15}$

In this work, we propose a comparative study of ALE processes for undoped, $c$-oriented, Ga-polar $\mathrm{GaN}$, relying both on $\mathrm{Cl}_{2}$ based plasma for the absorption step, but which are using two different rare gases for the activation step, namely, Ar and Kr. Indeed, while most of the literature is devoted to the optimization of the ALE process, thanks to discussions about the adsorption step and the choice of the chemistry for this step, less work has been done on the understanding of the role of the rare gas, which is generally argon. Two recent papers have begun to look into the phenomena. First, Sherpa et al. have shown that in the ALE of $\mathrm{Si}$ by $\mathrm{Cl}_{2} / \mathrm{Ar}$ plasma, ${ }^{16}$ the argon ions not only activate the modified $\mathrm{SiCl}_{\mathrm{x}}$ surface, which is crucial for the ALE window, but they also activate and create new $\mathrm{Cl}_{\mathrm{x}}$ adsorption sites (but no $\mathrm{Si}$ sputtering), which can increase the $\mathrm{Cl}_{2}$ saturation at the following adsorption steps. This surface modification by ion bombardment from $2 \mathrm{D}$ to " $3 \mathrm{D}$," porosity, or roughness can also be at the origin of the observed drift in the ALE process yield between the very first cycle and the others. Second, Berry et al. have discussed a plasma ALE process based on the idea that only the sputtering of a thin modified layer occurs without damaging the underneath unmodified film. ${ }^{17}$ Using a Monte Carlo collision cascade model, they predicted that depending on the rare gas used, a wider ALE window can be obtained for the ALE of tungsten. With this work, we will experimentally study this prediction for the ALE of GaN by comparing the use of two rare gas plasmas, namely, Ar and $\mathrm{Kr}$.

\section{EXPERIMENT}

Two ALE processes were developed in an inductively coupled plasma-reactive ion etching (ICP-RIE) etcher: RIE-200iP from SAMCO. In situ optical emission spectroscopy (OES) was used to monitor gas dissociation for the adsorption, activation, and purge steps, allowing the identification of active species. Additionally, OES monitoring was used to calibrate $\mathrm{Cl}_{2}$ dosing 
time and purging time to ensure complete separation of the $\mathrm{Cl}_{2}$ dissociation by-products and the gas used for the activation steps. The ICP source power $\left(\mathrm{RF}_{\text {source }}\right)$ and pressure for the adsorption step were varied in the $5-120 \mathrm{~W}$ range at $0.65 \mathrm{~Pa}$, respectively. For set adsorption step conditions, the DC self-bias $\left(\mathrm{V}_{\mathrm{DC}}\right)$ of the activation step was varied in the range of -11 to $-40 \mathrm{~V}$ by changing the ICP bias power $\left(\mathrm{RF}_{\text {bias }}\right)$; see the supplementary material ${ }^{31}$ for tables presenting the measured $\left|V_{D C}\right|$ corresponding to the $R_{\text {bias }}$ input. This assistance of substrate polarization in an ICP etcher ensures control of ion energy and enables activation through soft ionic bombardment calibrated to only sputter the modified layer. An Si wafer is introduced in the ICP reactor before conditioning the reactor chamber walls by an $\mathrm{Ar} / \mathrm{Cl}_{2}$ plasma at the same $\mathrm{RF}_{\text {source }}$ and $\mathrm{RF}_{\text {bias }}$ conditions used for the adsorption step for $1 \mathrm{~min}$. The reactor is then purged by $\mathrm{N}_{2}$. During conditioning and ALE processing, the ICP reactor chamber walls are kept at $150{ }^{\circ} \mathrm{C}$. The chuck is maintained at a temperature of $25^{\circ} \mathrm{C}$ by water circulation. Temperature homogenization to the $\mathrm{Si}$ wafer is ensured by a helium backside cooling.

For each condition, the etching rate per cycle (EPC) was estimated from the depth of etched GaN submitted to 200 ALE cycles using scanning electron microscopy images and reported as a function of $\mathrm{V}_{\mathrm{DC}}$ (from the activation step).

The specificity of our process is illustrated in Fig. 1(b): As far as the gases are concerned, pure rare gases ( $\mathrm{Ar}$ and $\mathrm{Kr}$ ) from Air Liquide were used. These gases were introduced in a continuous way, i.e., during all the steps including purge and activation steps. Considering $\mathrm{RF}_{\text {source, }}$ it is maintained at $50 \mathrm{~W}$ during adsorption and purge steps and increased in the 100-120 W range for the activation step, whereas $\mathrm{RF}_{\text {bias }}$ is only applied during the activation step. The advantage of this procedure is the possibility (i) to develop an ALE etching process in a conventional ICP etcher (no need of pulsed injection), (ii) to continuously monitor the ALE steps by OES, and (iii) to switch from conventional etching to ALE in the same process.

The samples consist of a $3 \mu \mathrm{m}$ undoped $c$-axis oriented $\mathrm{GaN}$ epilayer grown on a sapphire substrate by metal organic chemical vapor deposition. An $\mathrm{SiO}_{2}$ hardmask was deposited by sputtering and patterned by photolithography into an array of $3 \mu \mathrm{m}$-diameter holes with $2 \mu \mathrm{m}$ spacing. GaN/sapphire substrates were consecutively cleaned with acetone and then ethanol in an ultrasonic bath for $10 \mathrm{~min}$. Each GaN sample was then patched on a $150 \mathrm{~mm}$ diameter Si carrier wafer to be transferred. Before ALE processing, a soft sputtering of the $\mathrm{GaN}$ surface by $\mathrm{Ar}$ or $\mathrm{Kr}$ ions is performed for $30 \mathrm{~s}$, in order to remove any GaN native oxide.

\section{RESULTS AND DISCUSSION}

\section{A. Ar versus $\mathrm{Kr}$ rare gas plasma}

Figure 2 shows the results obtained for the EPC using exactly the same experimental conditions for all the ALE processing steps $\left(\mathrm{Cl}_{2}\right.$ plasma with a pressure of $\left.0.65 \mathrm{~Pa}\right)$, except the used rare gas, which was either Ar [Fig. 2(a)] or Kr [Fig. 2(b)]. Two features are revealed with the data presented in Figs. 2(a) and 2(b): (i) a clear plateau appears for the EPC when using $\mathrm{Kr}$ but not with $\mathrm{Ar}$ and (ii) a small increase in the EPC is observed for both activation gases, $\mathrm{Ar}$ and $\mathrm{Kr}$, when increasing $\mathrm{RF}_{\text {source }}$ during the activation step.

The first result clearly shows a $V_{D C}$ window, in the case of an activation step with $\mathrm{Kr}$ gas, for which a constant EPC is observed and is close to $0.52 \mathrm{~nm} /$ cycle. This value is in good agreement with the lattice constant of the GaN wurtzite crystal in the c-direction (5.189 $\AA$ ), which corresponds to two MLs of GaN. This regime was observed for $\mathrm{V}_{\mathrm{DC}}$ in the range of $[-16 \mathrm{~V},-22 \mathrm{~V}]$; see Fig. 2(b). For energies below the lower limit of the $\mathrm{V}_{\mathrm{DC}}$ window $(-16 \mathrm{~V})$, no measureable etched depth was observed from SEM images, hence the $0 \mathrm{~nm} /$ cycle attributed for these $V_{D C}$ values. For energies above the upper limit $(-22 \mathrm{~V})$, the EPC linearly increased with the increase in $\mathrm{V}_{\mathrm{DC}}$.

By contrast, for Ar gas, the presence of a similar regime is not clear at all; only a narrow range of $\mathrm{V}_{\mathrm{DC}}[-15 \mathrm{~V},-17 \mathrm{~V}]$ shows a smaller variation of EPC, around $0.4 \mathrm{~nm} /$ cycle, which corresponds to about $1.5 \mathrm{ML}$ of $\mathrm{GaN}$. For $\mathrm{V}_{\mathrm{DC}}$ values above $-17 \mathrm{~V}$, the EPC was found to increase, indicating an exit from the tenuous selflimited etching mode.

When increasing $\mathrm{RF}_{\text {source }}$ from 100 to $120 \mathrm{~W}$, a small increase of EPC is observed even on the constant EPC regime, for both Ar and $\mathrm{Kr}$ gases. This second result indicates an effect of the ion density on the overall EPC, as also observed by Sherpa et al. ${ }^{16}$ for the ALE of silicon with chlorine plasma.

\section{B. Self-limited steps}

Knowing that only $\mathrm{Kr}$ gas plasma gives rise to a clear constant EPC regime for a wide $V_{D C}$ window, we concentrated our study on (a)

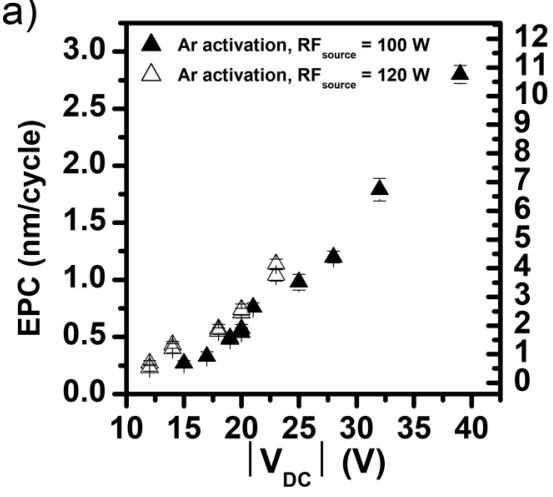

(b)

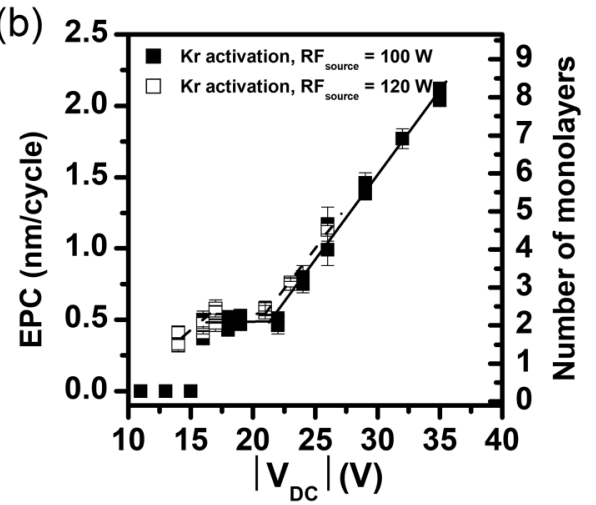

FIG. 2. EPC as a function of the absolute value of the self-bias potential $V_{D C}$ by varying $\mathrm{RF}_{\text {bias }}$ for (a) an activation by $\mathrm{Ar}$ plasma with an $\mathrm{RF}_{\text {source }}$ set at $100 \mathrm{~W}$ (full triangle) and $120 \mathrm{~W}$ (empty triangle) and (b) an activation by $\mathrm{Kr}$ plasma for an $\mathrm{RF}_{\text {source }}$ set at $100 \mathrm{~W}$ (full square) and $120 \mathrm{~W}$ (empty square). 
(a)

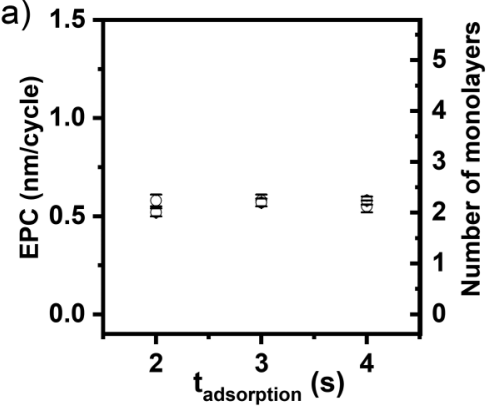

(b)

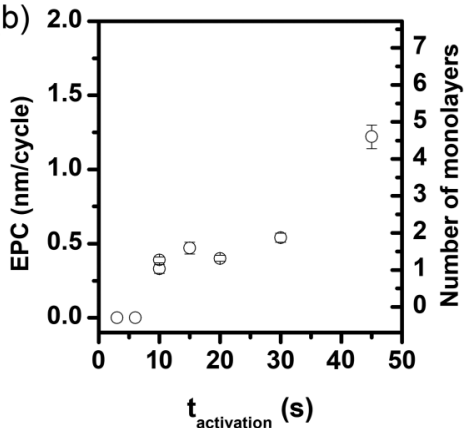

(c)

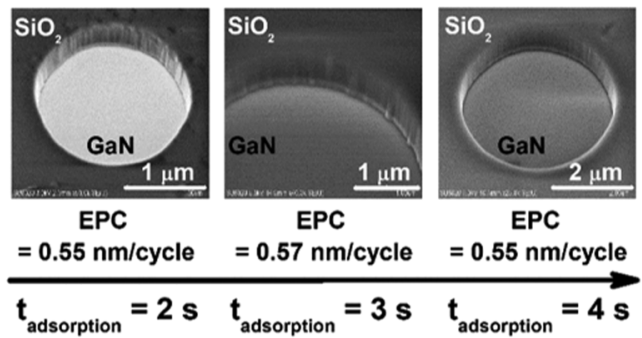

FIG. 3. EPC as a function of the adsorption time $t_{\text {adsorption }}$ (a) and the activation time $t_{\text {activation }}$ (b) for an in-window $\mathrm{Cl}_{2} / \mathrm{Kr}$ ALE condition as reported in Fig. 2(b); gas flows, $\mathrm{RF}_{\text {source, }} \mathrm{RF}_{\text {bias, }}$, and other time parameters are kept constant. SEM images of GaN surfaces (c) with an $\mathrm{SiO}_{2}$ hardmask corresponding to the adsorption time tadsorption investigated in (a).

the determination of self-limited behaviors for the adsorption and activation steps of our process, only for this rare gas. Figure 3 shows the stability of the EPC after changing the adsorption time $t_{\text {adsorption }}$ [Figs. 3(a) and 3(c)] with a constant $\mathrm{RF}_{\text {source }}$ set at $50 \mathrm{~W}$. For these experiments, the parameters of the activation steps were exactly the same. The EPC is constant over the studied parameter range, showing no additional impact on the EPC of the exposure time to the $\mathrm{Cl}_{2} / \mathrm{Kr}$ plasma.

As far as the activation step is concerned, the activation time $t_{\text {activation }}$ was varied over a large range of values from 5 to $50 \mathrm{~s}$, keeping all the other parameters constant; see Fig. 4. A wide time window presenting a constant EPC is observed for exposure times between 10 and $30 \mathrm{~s}$ with an EPC value around $0.5 \mathrm{~nm}$, in accordance with the EPC values obtained in Fig. 2(b). By contrast, for $t_{\text {activation }}$ above $30 \mathrm{~s}$, the EPC increased, indicating one or more additional phenomena for the etching mechanism.

\section{ALE synergy}

A quantitative way to scale the degree to which a process approaches the ideal ALE regime is the "ALE synergy" parameter S as defined by Kanarik et al. ${ }^{10}$ in Eq. (1),

$$
\operatorname{ALE} \text { synergy } \%(S)=\frac{\mathrm{EPC}-(\alpha+\beta)}{\mathrm{EPC}} \times 100 \% .
$$

EPC represents the material removed in one ALE cycle, averaging on either 200 completed ALE cycles or 400 cycles for the activation step. The values of $\alpha$ and $\beta$ are parasite etching contributions from individual steps, either adsorption or activation, when they are performed as independent processes. Ideally, synergy should approach $100 \%$ with no etching from either step alone. Figure 4(b) shows the results for the present case: $\alpha=0$, corresponding to no background etching detected with exposure to $\mathrm{Cl}_{2}$ plasma only; $\beta=0.20 \mathrm{~nm} / \mathrm{cycle}$, revealing that some sputtering of the $\mathrm{Kr}$ gas directly occurs on GaN materials. Having a value of EPC of $0.53 \mathrm{~nm} /$ cycle for ALE (full cycle), our synergy parameter is $62 \%$. This value is below the one expected knowing that the GaN has a strong surface binding energy, which is favorable to achieve a well-controlled ALE process (see Ref. 10). It is also less than the value of the synergy parameter S (0.90) reported by Ohba et al. ${ }^{14}$ who had, nevertheless, a self-limited EPC in the ALE regime, which is not as well fixed, compared to the one reported herein.

\section{Surface morphology}

From atomic force microscopy (AFM) observations, a significant decrease in the RMS roughness is obtained, from $0.18 \mathrm{~nm}$ for the as-deposited GaN surface to $0.07 \mathrm{~nm}$ after ALE processing. This smoothness is attributed to the layer-by-layer self-limiting nature of ALE as evidenced by contrast with the one obtained out of the ALE window $(0.43 \mathrm{~nm})$.

\section{E. Discussion}

For activation by both $\mathrm{Ar}$ and $\mathrm{Kr}$ ions, the observed plateaus for the EPC at 0.4 and $0.52 \mathrm{~nm} /$ cycle, respectively, illustrate the concept of the ALE window as defined by Kanarik et al. ${ }^{9}$ It allows

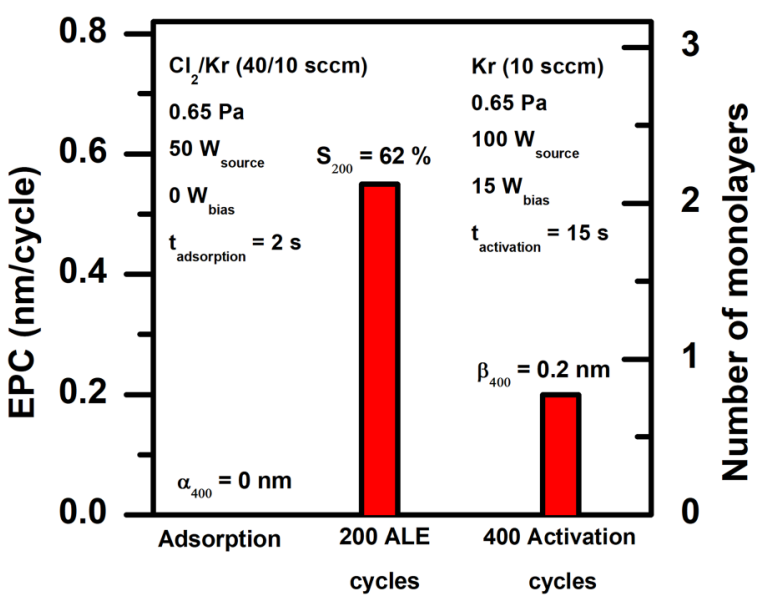

FIG. 4. Results of the $\mathrm{Cl}_{2} / \mathrm{Kr}$ ALE synergy test. EPC after exposure to adsorption only and activation only for 400 cycles. In the middle bar, adsorption and activation are combined at the same conditions into an ALE for 400 cycles. 
identification of an ALE window for a range of ion energies equivalent to $\mathrm{V}_{\mathrm{DC}}$ windows of $[-16 \mathrm{~V},-22 \mathrm{~V}]$ and $[-15 \mathrm{~V},-17 \mathrm{~V}]$, respectively, for $\mathrm{Kr}$ and $\mathrm{Ar}$ ions, for which the modified surface material assumed to be formed at the adsorption step is completely removed during the activation step. For Ar activation, the EPC at the ALE window is in good agreement with values in the 0.37$0.42 \mathrm{~nm} /$ cycle reported in the literature for ALE of GaN with $\mathrm{Ar}$ ion activation. ${ }^{14,15}$ For energies below the lower limit of the ALE window, $-16 \mathrm{~V}$ and $-15 \mathrm{~V}$, respectively, removal of the modified layer is assumed to be inexistent or incomplete due to insufficient energy for the incoming ions. For energies above the upper limit, $-22 \mathrm{~V}$ and $-17 \mathrm{~V}$, respectively, sputtering of bulk materials occurs without any self-limitation once the removal of the modified layer is completed. Sputtering thresholds in pristine Ga-polar GaN (0001) have been reported to be close to $100 \mathrm{eV}$ and in the $250-400 \mathrm{eV}$ range, ${ }^{18}$ for $\mathrm{N}$ atoms and $\mathrm{Ga}$ atoms, respectively. The $\mathrm{V}_{\mathrm{DC}}$ values reported here are not incompatible: the upper value reported for $\mathrm{Ar}$ ion activation is in good agreement with a $\mathrm{V}_{\mathrm{DC}}$ of $-16 \mathrm{~V}$ reported for the ALE of GaN with Ar activation in an ICP etcher reported by Kauppinen et al. ${ }^{15}$

The presence of a modified GaN layer at the end of the adsorption step is evidenced by the ALE synergy data presented in Fig. 4 and a lower EPC of $0.20 \mathrm{~nm} /$ cycle for the $\mathrm{Kr}$ adsorption step alone. These results also exclude direct $\mathrm{Kr}$ sputtering as an origin for the $0.52 \mathrm{~nm} /$ cycle at the ALE window, shown in Fig. 2(b). The nature of the modified layer formed at the surface of Ga-polar $\mathrm{GaN}$ (0001) has not yet been clearly experimentally identified. It is currently speculated to involve the adsorption of chlorine radicals and neutrals diffusing from the plasma to the Ga-polar surface ${ }^{14,19}$ and/or the direct physisorption of nondissociated $\mathrm{Cl}_{2},{ }^{15}$ leading to the desorption of volatile by-products upon ionic bombardment at the activation step: $\mathrm{GaCl}_{3},{ }^{14} \mathrm{GaCl}_{2},{ }^{15} \mathrm{GaCl}, \mathrm{GaNCl}$, and $\mathrm{Ga}_{2} \mathrm{NCl}_{2}{ }^{19}$ The underlying $\mathrm{N}$ dangling bonds are expected to recombine into $\mathrm{N}_{2}$ due to favorable high binding energy rather than from an $\mathrm{N}$-rich surface. ${ }^{20}$ The constant EPC as a function of $t_{\text {adsorption }}$ presented in Fig. 3(a) confirms a clear self-limited saturation of available adsorption sites by chlorine species at the surface, as no increase of EPC occurs when increasing $t_{\text {adsorption }}$ for identical $\mathrm{Kr}$ activation steps (same $\mathrm{RF}_{\text {source }}$ and $\mathrm{RF}_{\text {bias }}$ conditions).

We try to explain the difference in width for the observed ALE window between $\mathrm{Ar}$ and $\mathrm{Kr}$ ion gases, following the approach developed by Berry et al. ${ }^{17}$ In their sputtering model, if you have a conserved momentum transfer, the sputtering yield should be ion mass dependent, especially for high atomic mass materials. They simulate that, for light material (titanium), the ion mass in the removal step does not change the ALE curve, whereas for the heavier one (tungsten), it is better to use a light rare gas such as neon instead of argon. Our experimental results confirm qualitatively the strong dependence of the ALE regime with the ion mass of the removal species, but not with the tendency predicted by Berry et al., ${ }^{17}$ i.e., the lighter the ion mass the larger the ALE window. In addition, the narrower ALE window for Ar ions could also originate from the difference in the ion energy distribution between $\mathrm{Ar}$ and $\mathrm{Kr}$ ions. The ion energy distribution for Ar plasma has been reported to be often wider than the ALE window., ${ }^{9}$

Kawakami et al. ${ }^{21}$ reported a comparison of the GaN etching damage with both $\mathrm{Kr}$ and Ar plasma by using a capacitively coupled radio frequency plasma generator. Kr plasma allows obtaining a smoother surface, a thinner etching depth, and a preferential etching of $\mathrm{Ga}$ species compared with Ar plasma, which leads to a preferential etching of $\mathrm{N}$ species and significant roughness of the $\mathrm{GaN}$ etched surface. The discrepancy observed between the difference in EPC at the ALE window between $\mathrm{Kr}$ ions (equivalent to two MLs of GaN) and $\mathrm{Ar}$ ions (equivalent to $1.5 \mathrm{ML}$ of $\mathrm{GaN}$ ) presented in this study and the thinner etch depth for $\mathrm{Kr}$ ions compared with $\mathrm{Ar}$ ions reported by Kawakami et al. ${ }^{21}$ is still not clear. Two origins can be considered: (i) a partial removal of two modified MLs of GaN formed at the end of the adsorption step by Ar ions, compared with a full removal by $\mathrm{Kr}$ ions, or (ii) an overetch of one ML of GaN by $\mathrm{Kr}$ ions after removal of a single chlorinated GaN ML at the end of the adsorption, induced by the preferential etching of $\mathrm{Ga}$ atoms of the second ML. If we consider the case of adsorption of chlorine atoms for the formation of the modified layer, the optimal distance between chlorine atoms has been calculated to be greater than or equal to $0.36 \mathrm{~nm}^{22}$ The distance between two neighboring $\mathrm{Ga}$ atoms on a (0001) GaN surface is $0.319 \mathrm{~nm}$. The mismatch is expected to lead to steric hindrances between $\mathrm{Cl}$ atoms impeding the full coverage of the surface and leaving nonpaired Ga atoms. Coverage of the Si surface by chlorine atoms has been reported in the $30 \%-50 \%$ range $^{23,24}$ and has been estimated to reach a maximum of $50 \%$ for the ALE of silicon. ${ }^{16,25}$ Similar coverage is to be expected for the Ga-polar surface, excluding the first hypothesis. By assumption, a partial chlorination of only one ML of GaN, a preferential etching of the nonpaired $\mathrm{Ga}$ atoms by $\mathrm{Kr}$ ions compared with $\mathrm{Ar}$ ions could explain a difference in EPC, but it should yield at best, in the case of a self-limited activation, to an EPC of one ML and inferior to one $\mathrm{ML}$ for $\mathrm{Kr}$ and $\mathrm{Ar}$ ions, respectively. However, the preferential etching of $\mathrm{Ga}$ species by $\mathrm{Kr}$ ions could explain the especially low RMS roughness of $0.07 \mathrm{~nm}$, reported in Fig. 5(e). By contrast, the higher propensity of Ar sputtering for damage introduction and the lack of assistance for removing nonpaired Ga atoms could explain the significantly higher RMS roughness at $1.9 \mathrm{~nm}$ reported for Ar activation based ALE of GaN. ${ }^{15}$ The overetch per cycle of 1 and $0.4 \mathrm{ML}$ for activation by $\mathrm{Kr}$ ions and $\mathrm{Ar}$ ions, respectively, could originate in a too-high $\mathrm{RF}_{\text {source }}$ and/or $\mathrm{RF}_{\text {bias }}$ used for the activation step: as a consequence, the synergetic effect ${ }^{26}$ of neutral (chlorine radicals) and $\mathrm{Kr}$ ion bombardment during the adsorption and activation steps, respectively, is not completely separated in the process. This contrasts with the molecular dynamics simulation carried out on chemical sputtering of $\mathrm{Cl}$-adsorbed wurzite $\mathrm{GaN}$ (0001) surfaces by $\mathrm{Ar}$ ions: ${ }^{19} \mathrm{Ga}$ is mainly sputtered in the form of $\mathrm{Ga}_{-} \mathrm{Cl}_{2}$, but $\mathrm{Ga}$ sputtering does not take place at all on the clean surface for $\mathrm{RF}_{\text {source }}$ as large as $250 \mathrm{~W}$. Finally, the presence of partially oxidized GaN at the surface originating from cross-contamination by oxygen desorbing from the $\mathrm{SiO}_{2}$ hardmask could lead to a difference in EPC if we consider a lower sputtering rate from $\mathrm{Ar}$ ions compared to $\mathrm{Kr}$ ions. The amount of desorbed oxygen is expected to be limited and not allow a full coverage of the GaN surface, as no degradation of the $\mathrm{SiO}_{2}$ hardmask was observed. However, only in situ XPS measurements would allow us to definitely exclude this possibility. While one of the hypotheses presented here could be contributing to the higher EPC at the ALE window observed for activation by $\mathrm{Kr}$ ions, nevertheless, additional mechanisms may contribute also. 


\section{No etching}

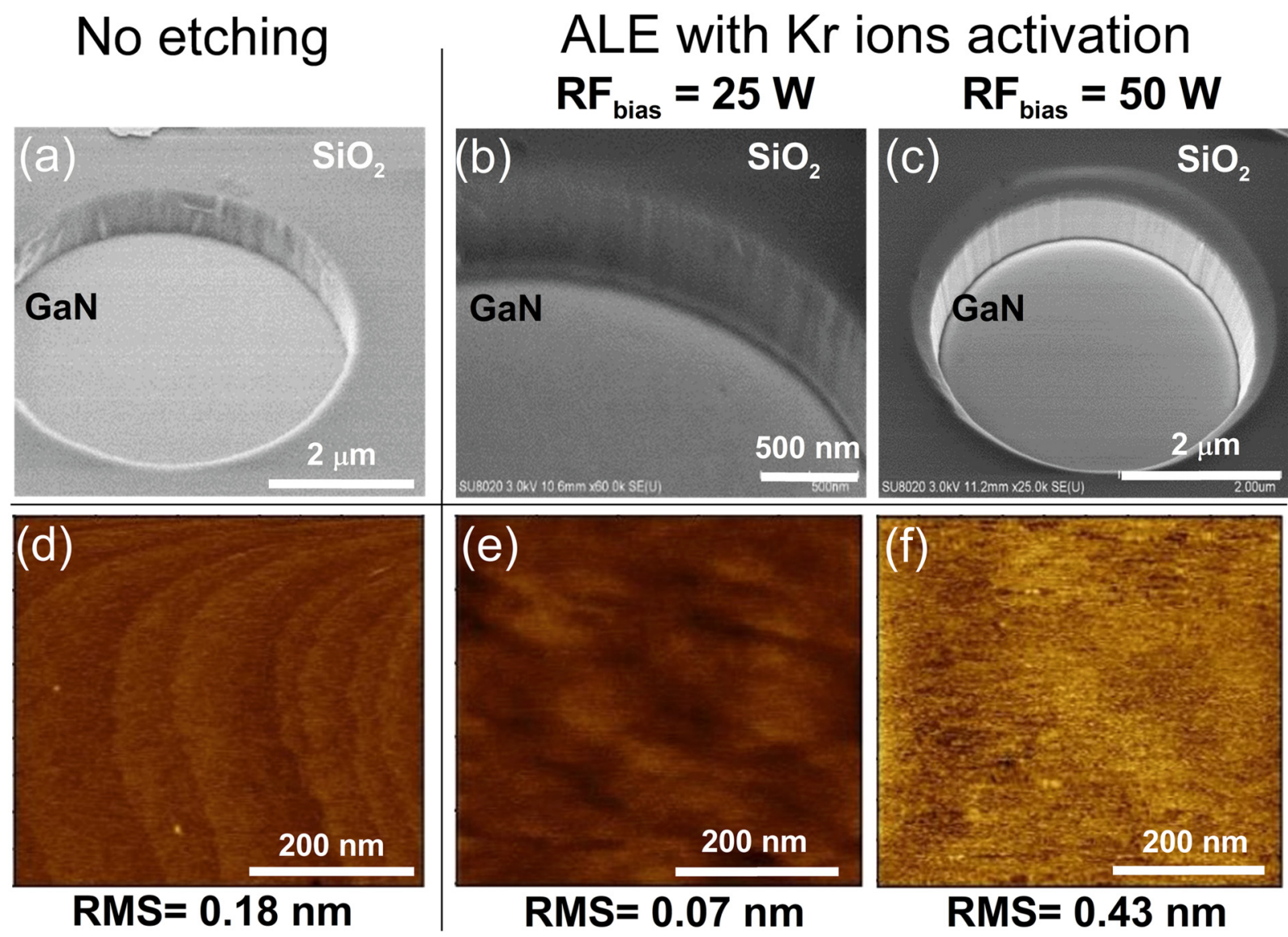

FIG. 5. SEM images of $\mathrm{GaN}$ surfaces with an $\mathrm{SiO}_{2}$ hardmask: before etching (a) and after 200 cycles of the $\mathrm{Cl}_{2} / \mathrm{Kr} \mathrm{ALE}$ process in the $\mathrm{ALE}$ window (b) and out of the ALE window (c). AFM images and RMS roughness of GaN surfaces: before etching (d) and after 200 cycles of the $\mathrm{Cl}_{2} / \mathrm{Kr} \mathrm{ALE}$ process in the ALE window (e) and out of the ALE window (f).

Considering the small increase in EPC, even on the ALE plateau, when increasing the $\mathrm{RF}_{\text {source }}$ for both $\mathrm{Ar}$ and $\mathrm{Kr}$ gases, similar EPC variations were reported by Sherpa et al. ${ }^{16}$ for the ALE of silicon with chlorine plasma in a capacitively coupled plasma etcher. The authors associated this trend with an increase in adsorption sites during the ALE process. The increase in the ion density and ion flux, by increasing $\mathrm{RF}_{\text {source }}$ from 100 to $120 \mathrm{~W}$, leads to the creation at the nth activation step of additional adsorption sites for chlorine species at the following $(n+1)$ th adsorption step. The mechanisms for the creation of these additional active sites are still unclear, but the following mechanisms have been proposed for silicon by Sherpa et al.: ${ }^{16}$ desorption of contaminants, ${ }^{27}$ reductions in steric hindrances ${ }^{25}$ between adsorbed chlorine species due to lattice deformations, ${ }^{24,28}$ or creation of subsurface binding sites ${ }^{29}$ upon ionic bombardment. This effect could be cumulative from the repetition of the activation step: as a consequence, the EPC reported in this study, averaged on 200 cycles, is not fully indicative to the instant etch depth at a given nth cycle.

In regard to the above discussion, the difference in EPC obtained at the ALE window between the two ion gases could be explained from the difference in the additional adsorption site density introduced by the ionic bombardment for $\mathrm{Ar}$ and $\mathrm{Kr}$ ions. Such differences could arise from the difference in the ion mass, as mentioned earlier. It could be further widened by the higher ion fluxes obtained for $\mathrm{Kr}$ plasma compared with $\mathrm{Ar}$ plasma for the same $\mathrm{RF}_{\text {source }}$ condition, originating from the lower ionization energy required for $\mathrm{Kr}(13.96 \mathrm{eV})$ compared with Ar $(15.75 \mathrm{eV}) .^{21}$

The drift of EPC from an average of 0.5 to $1.18 \mathrm{~nm} /$ cycle for $t_{\text {activation }}$ above $30 \mathrm{~s}$, shown in Fig. 3(b), illustrates a dose effect for the ionic bombardment impacting the EPC yield. High disordering and weakening of the GaN lattice induced by long exposure to soft ionic bombardment is assumed to either reduce the binding energy below the 8.6-9.12 eV range reported for the pristine GaN (0001) range $^{1,14,21}$ and reduce the threshold energy required for ions to sputter or drastically increase the density of adsorption sites at the $\mathrm{GaN}$ surface. In addition, the too-high value obtained for EPC when dealing only with $\mathrm{Kr}$ sputtering (Fig. 4) could then be explained by the dose effect mentioned above: we average here the EPC over 400 cycles and not 200 as for the completed ALE cycles, leading to an overestimated EPC. 
These results reveal the nonideal achievement of the ALE condition for $\mathrm{Kr}$ ions: indeed, ion bombardment during the activation step, besides removing the modified layer, may also generate additional active sites for the adsorption of chlorine species. In other words, these results reveal that the usual assumption in ALE, that is, the steps of adsorption and desorption are fully decoupled, is not totally valid here and that more intricate relations between these two steps are at play.

\section{SUMMARY AND CONCLUSIONS}

ALE of Ga-polar GaN (0001) using a standard ICP-RIE system is achieved in this work. We have investigated the use of two rare gas plasmas for the activation step, namely, $\mathrm{Ar}$ and $\mathrm{Kr}$, and show a much larger and well-defined ALE window for the latter, always using chlorine for the adsorption step. The GaN ALE process is demonstrated by etching mesa structures masked with a photoresist. A self-limited etching rate per cycle of two monolayers is obtained. This provides an atomic-scale process for nanofabrication, knowing in addition that the smoothness of the structure is increased.

Further work is needed to understand the limitation of the synergy parameter and to identify the species in the modified layer after the adsorption step by doing some XPS measurements. Moreover, a comparison of the two polar GaN (0001) surfaces, Ga and $\mathrm{N}$, will be done to elucidate the influence of surface structures ( Ga or $\mathrm{N}$ dangling bonds ${ }^{30}$ ) on the achievement of a well-controlled ALE regime.

\section{ACKNOWLEDGMENTS}

The authors devote this article to the memory of C. You who was working with them on this subject for her Ph.D. thesis as a student of both the University of Grenoble-Alpes and the University of Tsukuba who suddenly passed away. This work was achieved in the frame of a joint research and educational program between the University of Tsukuba and Universite Grenoble-Alpes. The authors would like to thank Masahiro Sasaki from the University of Tsukuba for his support and advice on this work. This study was supported by the Laboratoire d'Excellence LANEF in Grenoble (No. ANR-10-LABX-51-01).

\section{REFERENCES}

${ }^{1}$ A. David, B. Moran, K. McGroddy, E. Matioli, E. L. Hu, S. P. DenBaars, S. Nakamura, and C. Weisbuch, Appl. Phys. Lett. 92, 113514 (2008).

${ }^{2}$ W. Harrison, Electronic Structure and the Properties of Solids (Dover, New York, 1989).

${ }^{3}$ K. Eriguchi, Jpn. J. Appl. Phys. 56, 06HA01 (2017).
${ }^{4}$ C. H. Chen, S. Keller, E. D. Haberer, L. Zhang, S. P. Denbaars, E. L. Hy, and Y. Wu, J. Vac. Sci. Technol. B 17, 2755 (1999).

${ }^{5}$ W. Shockleyand and W. T. Read, Jr., Phys. Rev. 87, 835 (1952).

${ }^{6}$ R. Calarco, M. Marso, T. Richter, A. I. Aykanat, R. Meijers, A. V. D. Hart, T. Stoica, and H. Lüth, Nano Lett. 5, 981 (2005).

${ }^{7}$ K. J. Choi, H. W. Jang, and J. L. Lee, Appl. Phys. Lett. 82, 1233 (2003).

${ }^{8}$ T. Faraz, F. Roozeboom, H. C. M. Knoops, and W. M. M. Kessels, ECS J. Solid State Sci. Technol. 4, 5023 (2015).

${ }^{\mathbf{9}}$ K. J. Kanarik, T. Lill, E. A. Hudson, S. Sriraman, S. Tan, J. Marks, V. Vahedi, and R. A. Gottscho, J. Vac. Sci. Technol. A 33, 020802 (2015).

${ }^{10}$ K. J. Kanarik et al., J. Vac. Sci. Technol. A 35, 05C302 (2017).

${ }^{11}$ D. Buttari, S. Heikman, S. Keller, and U.K. Mishra, Proceedings of the IEEE Lester Eastman Conference on High Performances Devices, Newark, DE, 8 August 2002 (IEEE, New York, 2002), p. 461.

${ }^{12}$ S. D. Burnham, K. Boutros, P. Hashimoto, C. Butler, D. W. S. Wong, M. Hu, and M. Micovic, Phys. Status Solidi C 7, 2010 (2010).

${ }^{13}$ D. H. van Dorp, S. Arnauts, F. Holsteyns, and S. De Gendt, ECS J. Solid State Sci. Technol. 4, N5061 (2015).

${ }^{14}$ T. Ohba, W. Yang, S. Tan, K. J. Kanarik, and K. Nojiri, Jpn. J. Appl. Phys. 56, 06HB06 (2017).

${ }^{15}$ C. Kauppinen, S. A. Khan, J. Sundqvist, D. B. Suyatin, S. Suihkonen, E. I. Kauppinen, and M. Sopanen, J. Vac. Sci. Technol. A 35, 060603 (2017).

${ }^{16}$ S. D. Sherpa, P. L. G. Ventzek, M. Lee, G. S. Hwang, and A. Ranjan, J. Vac. Sci. Technol. A 36, 031303-1 (2018).

${ }^{17}$ I. L. Berry, K. J. Kanarik, T. Lill, S. Tan, V. Vahedi, and R. A. Gottscho, J. Vac. Sci. Technol. A 36, $01 \mathrm{~B} 105$ (2018).

${ }^{18}$ K. Harafuji and K. Kawamura, Jpn. J. Appl. Phys. 47, 1536 (2008).

${ }^{19}$ K. Harafuji and K. Kawamura, Jpn J. Appl. Phys. 49, 08JE03 (2010).

${ }^{\mathbf{2 0}}$ J. Sellés et al., Appl. Phys. Lett. 109, 231101 (2016).

${ }^{21}$ R. Kawakami, T. Inaoka, K. Tominaga, and T. Mukai, Jpn J. Appl. Phys. 48, 08HF01 (2009).

${ }^{22}$ S. Rivillon, Y. J. Chabal, L. J. Webb, D. J. Michalak, N. S. Lewis, M. D. Halls, and K. Raghavachari, J. Vac. Sci. Technol. A 23, 1100 (2005).

${ }^{\mathbf{2 3}}$ T. Matsuura, J. Murota, Y. Sawada, and T. Ohmi, Appl. Phys. Lett. 63, 2803 (1993).

${ }^{\mathbf{2 4}}$ S. D. Athavale and D. J. Economou, J. Vac. Sci. Technol. B 14, 3702 (1996).

${ }^{25}$ G. Kresse and J. Furthmuller, VASP: The Guide (Vienna University of Technology, Vienna, 2001).

${ }^{26}$ J. W. Coburn and H. F. Winters, J. Appl. Phys. 50, 3189 (1979).

${ }^{\mathbf{2 7}}$ A. Ranjan, M. Wang, S. D. Sherpa, V. Rastogi, A. Koshiishi, and P. L. G. Ventzek, J. Vac. Sci. Technol. A 34, 31304 (2016).

${ }^{28}$ N. C. M. Fuller, D. A. Telesca, V. M. Donnelly, and I. P. Herman, Appl. Phys. Lett. 82, 4663 (2003).

${ }^{29}$ N. Layadi, V. M. Donnelly, and J. T. C. Lee, J. Appl. Phys. 81, 6738 (1998).

${ }^{30} \mathrm{M}$. Hasegawa, T. Tsutsumi, A. Tanide, H. Kondo, K. Ishikawa, M. Sekine, and M. Hori, "In situ surface analysis of Ga dangling sites and chlorination layers for determining atomic layer etching properties of GaN," presented at 12th AsianEuropean International Conference on Plasma Surface Engineering, Jeju Island, Korea, 1-5 September 2019 (unpublished).

${ }^{31}$ See supplementary material at https://doi.org/10.1116/1.5134130 for tables of measured DC self-bias and ICP bias power input. 